\title{
Effect of the T6 Heat Treatment on Microhardness of a Directionally Solidified Aluminum- Based 319 Alloy
}

\author{
Igor Alexsander Barbosa Magno ${ }^{a}$, Fabricio Vinicius Andrade de Souza ${ }^{a}$, André dos Santos Barros, \\ Marlo Oliveira Costa ${ }^{b}$,Jacson Malcher Nascimento ${ }^{a}$, Thiago Antônio Paixão de Sousa Costa ${ }^{b}$, Otávio \\ Fernandes Lima da Rocha ${ }^{a, b *}$ \\ ${ }^{a}$ Universidade Federal do Pará - UFPA, Rua Augusto Corrêa, 1, 66075-970, Belém, PA, Brazil \\ ${ }^{b}$ Instituto de Educação, Ciência e Tecnologia do Pará, Avenida Almirante Barroso, 1155, 66093-020, \\ Belém, PA, Brazil
}

Received: December 10, 2016; Revised: October 13, 2017; Accepted: October 18, 2017

\begin{abstract}
Aluminum alloys of the ANSI series 319 present $\mathrm{Si}$ and $\mathrm{Cu}$ as the main alloying elements and the mechanical strength of these alloys can be improved by the precipitation of the metastable $\mathrm{Al}_{2} \mathrm{Cu}$ phase during the ageing heat treatment. In this paper, the Al-5.5wt.\% $\mathrm{Si}-3 \mathrm{wt} . \% \mathrm{Cu}$ alloy was elaborated and solidified in a water-cooled horizontal directional solidification device. The as-cast ingot was subjected to the precipitation hardening heat treatment (T6 heat treatment), which consisted of: solution for $5 \mathrm{~h}$ at $490^{\circ} \mathrm{C} \pm 2^{\circ} \mathrm{C}$, followed by quenching in water at $60^{\circ} \mathrm{C} \pm 2^{\circ} \mathrm{C}$ and ageing for $3 \mathrm{~h}$ at $155^{\circ} \mathrm{C} \pm 2^{\circ} \mathrm{C}$, and cooling-air. Secondary dendrite arm spacing $\left(\lambda_{2}\right)$ measurements were carried out before and after T6 heat treatment. The mechanical strength of the alloy was investigated by the microhardness test. It has been found that the heat treatment did not influence the $\lambda_{2}$ values, however, highest HV values have been observed for the heat-treated samples.
\end{abstract}

Keywords: T6 Heat Treatment, Microstructure, Al-Cu-Si Alloys.

\section{Introduction}

It is known that among metals of major industrial interest, aluminum is a new material, compared, for example, with iron, copper, tin, lead, etc. The industry's interest in aluminum is due to its high strength/weight ratio. In addition, it is corrosion resistant and has a high electrical and thermal conductivity. Other elements in controlled composition are added to improve specific properties. Addition of $\mathrm{Si}$, for example, increases the fluidity and decreases the solidification shrinkage, resulting in an increase in castability. The addition of copper to the Al-Si alloy causes the formation of $\mathrm{Al}_{2} \mathrm{Cu}$ phase and other intermetallic compounds, which increases mechanical strength and enables hardening by heat treatment. In unmodified alloys copper is present primarily as $\mathrm{Al}_{2} \mathrm{Cu}$ or $\mathrm{Al}-\mathrm{Al}_{2} \mathrm{Cu}-\mathrm{Si}$ eutectic phase.

Aluminum-based multicomponent alloys, especially those of the 319 series [Al-(3-4)wt.\%Cu-(5.5-10)wt.\%Si] have attracted attention of many researchers, engineers and designers as promising structural materials and are now being employed with growing frequency in automotive industry or aerospace applications ${ }^{1}$. In 319 alloys, the copper intermetallic phase $\left(\mathrm{Al}_{2} \mathrm{Cu}\right)$, the porosity size and distribution, the morphology, size, and distribution of eutectic silicon particle, and the degree of supersaturation of $\mathrm{Cu}$ in the $\alpha$-Al matrix, after solution heat treatment, are the main parameters expected to control the mechanical propertie $\mathrm{e}^{1,2}$. Is is known that the increasing on hardness is due to $\mathrm{Al}_{2} \mathrm{Cu}$

*e-mail: otvrocha@oi.com.br phase precipitation in the aluminum dendritic network and changes on silicon morphology ${ }^{1,2}$.

The Aluminum Association has standardized the definitions and nomenclature for heat treatment, which involves the following stages ${ }^{3}$.

1. Solution treatment at a relatively high temperature to dissolve the $\mathrm{Al}_{2} \mathrm{Cu}$ intermetallic, formed during solidification;

2. Quenching, usually to temperature controled, to obtain a supersaturated solid solution;

3. Age hardening, to cause precipitation from the supersaturated solid solution, either at room temperature (natural ageing) or at an elevated temperature (artificial ageing).

It is observed by the solidification path of the investigated $\mathrm{Al}-\mathrm{Cu}-\mathrm{Si}$ alloy that three main phases are formed, which are: (1) Al-rich primary phase ( $\alpha$-Al), constituted of a dendritic network; (2) secondary phase, with lamellar silicon particles and (3) tertiary phase, formed by the $\mathrm{Al}_{2} \mathrm{Cu}$-stoichiometric intermetallic compound. The iron element is present in the composition of aluminum-based alloys, it is often regarded as an undesirable impurity as it forms long and brittle $\beta-\mathrm{Al}_{5} \mathrm{FeSi}$ plates that initiate and link fracture, in addition to other Fe intermetallics that appear with the solidification. Costa et $\mathrm{al}^{1}$ has presented the solidification path of the $\mathrm{Al}-3 \mathrm{wt} \% \mathrm{Cu}-$ $5.5 \mathrm{wt} \% \mathrm{Si}$ alloy and the Figure 1 schematizes the phase transformations that occur the its during solidification. The defects, the morphology of eutectic and the morphology of intermetallic phases have an important effect on the ultimate mechanical properties of the casting ${ }^{1-4}$. 


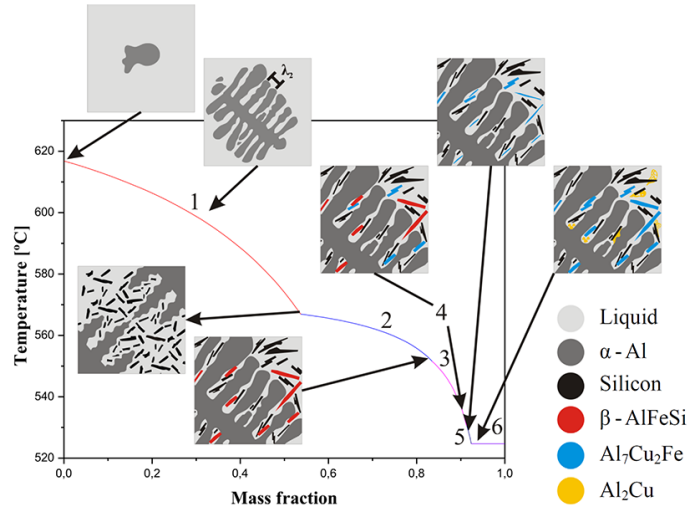

Figure 1. Solidification path of the investigated alloy: Reactions occurring during the solidification process.

Thus, this work aimed to characterize and quantify the microstructure, before and after T6-heat treatment, in samples of a horizontally solidified Al- $-5.5 \mathrm{wt} \% \mathrm{Si}-3.0 \mathrm{wt} \% \mathrm{Cu}$ alloy. Standard metallographic techniques were applied to characterize and quantify the secondary dentrite arm spacings. Finally, microhardness measurements (HV) have been carried out and plotted with position along the casting ingot.

\section{Experimental Procedure}

The casting assembly used in the horizontal directional solidification (HDS) experiment has been detailed in a previous article ${ }^{5,6}$. This solidification setup was designed in such way that heat was extracted only through the watercooled lateral metal/mold, promoting horizontal directional solidification. The directional solidification experiment was carried out with a nominal composition of Al-5.5wt.\% $\mathrm{Si}-$ $3.0 \mathrm{wt} . \% \mathrm{Cu}$ alloy. Continuous temperature measurements in the casting were monitored during the HDS through the output of a bank of fine type $\mathrm{K}$ thermocouples sheathed in $1.6 \mathrm{~mm}$ steel tubes and positioned at 5, 15,30,50,70 e $90 \mathrm{~mm}$ from the chill. The results of experimental thermal analysis have been used to determine the displacement of the liquidus isotherm, i.e., a plot of position from the metal/ mold interface as a function of time corresponding to the liquidus front passing by each thermocouple.

The T6 heat treatment, which was performed according to the methodology proposed by Costa et $\mathrm{al}^{1}$ and Jerry et $\mathrm{al}^{7}$, consisted of:

a) solution heat treatment for $5 \mathrm{~h}$ at $490^{\circ} \mathrm{C} \pm 2^{\circ} \mathrm{C}$;

b) quenching in warm water at $60^{\circ} \mathrm{C} \pm 2^{\circ} \mathrm{C}$;

c) immediate aging for $3 \mathrm{~h}$ at $155^{\circ} \mathrm{C} \pm 2^{\circ} \mathrm{C}$;

d) air cooling.

The solution treatment aimed to dissolve the equilibrium $\mathrm{Al}_{2} \mathrm{Cu}$ intermetallic particles in the Al-rich matrix $(\alpha-\mathrm{Al})$ and with the quenching in warm water to obtain a supersaturated solid solution $\left(\alpha-\mathrm{Al}_{\text {sss }}\right)$ with the formation of an $\mathrm{Al}_{2} \mathrm{Cu}$ - intermetallic metastable phase dispersed in $\alpha-\mathrm{Al}_{\mathrm{sss}}$ solution, whose phase was precipitated with the artificial aging treatment. Figure 2 shows a schematic representative of the stages performed during the T6-heat treatment.

The rectangular shaped ingot was sectioned along its longitudinal axis to reveal the macrostructure. One of the sectioned parts of the as-cast ingot was used to develop the heat-treatment. Samples for metallographic analysis have been extracted from the as-cast and heat-treated ingots. In order to characterize and quantify the dendritic structure, selected longitudinal sections of the as-cast and heat-treated part (in positions $3,5,10,15,20,30,40,50,60,80$ and $100 \mathrm{~mm}$ from the metal/mold interface) were polished and etched with an acid solution ( $\mathrm{NaOH} 5 \%$ ) for microstructural analysis. The secondary dendrite arm spacing was measured by averaging the distance between adjacent side branches on longitudinal sections of primary dendrite stalks ${ }^{8}$. Figure 3a presents the macrostructure of the investigated alloy, showing the removal region of the samples for analysis of the microstructure. Figure $3 \mathrm{~b}$ shows the methodology developed for $\lambda_{2}$ measuring.

The Vickers microhardness test consisted of applying a load through a pyramidal of square base shape indenter made of diamond and supposed to carry out on flat, polished and clean surface. The corresponding positions were $3,5,10$, $15,20,30,40,50,60,80$ and $100 \mathrm{~mm}$. Microhardness tests

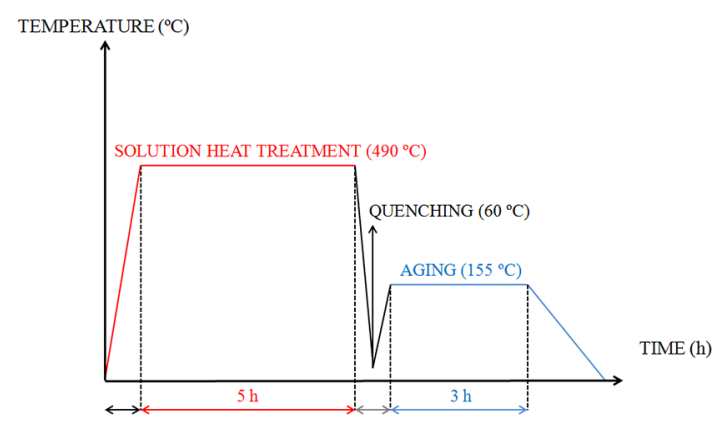

Figure 2. Schematic representation of the stages of the T6-heat treatment applied in this work.

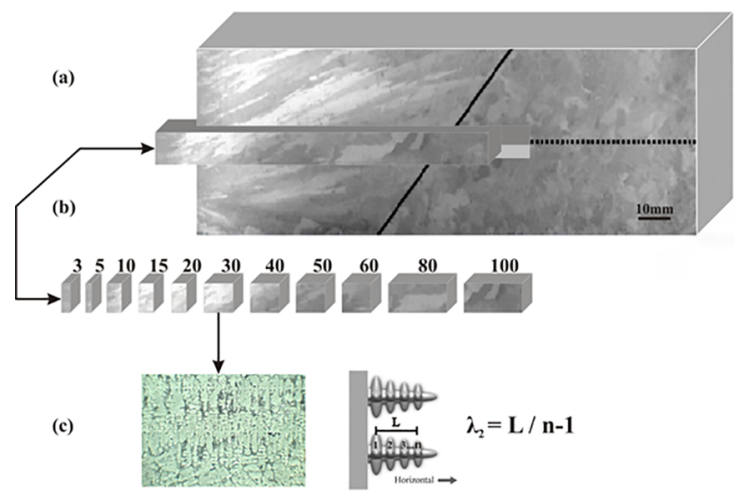

Figure 3. (a) Solidification macrostructure, (b) Removal of samples for microstructural analysis and (c) Technique used for $\lambda_{2}$ measuring. 
were conducted on each sample using a $50 \mathrm{~g}$ load and a dwell time of $10 \mathrm{~s}$, as proposed by Çadirli ${ }^{9}$ and Kaya et $\mathrm{al}^{10}$. The adopted Vickers microhardness values are the average of at least 20 different measurements on the transverse section of each sample, using the methodology proposed by Barros et $\mathrm{al}^{11}$ and Guimaraes ${ }^{12}$. The minimum distances for indentations have been defined by ASTM E384 ${ }^{13}$, ASTM E- $92^{14}$ and ASM HANDBOOK ${ }^{15}$. Representative scheme of HV measurement in the analyzed samples can be seen in Figure 4.

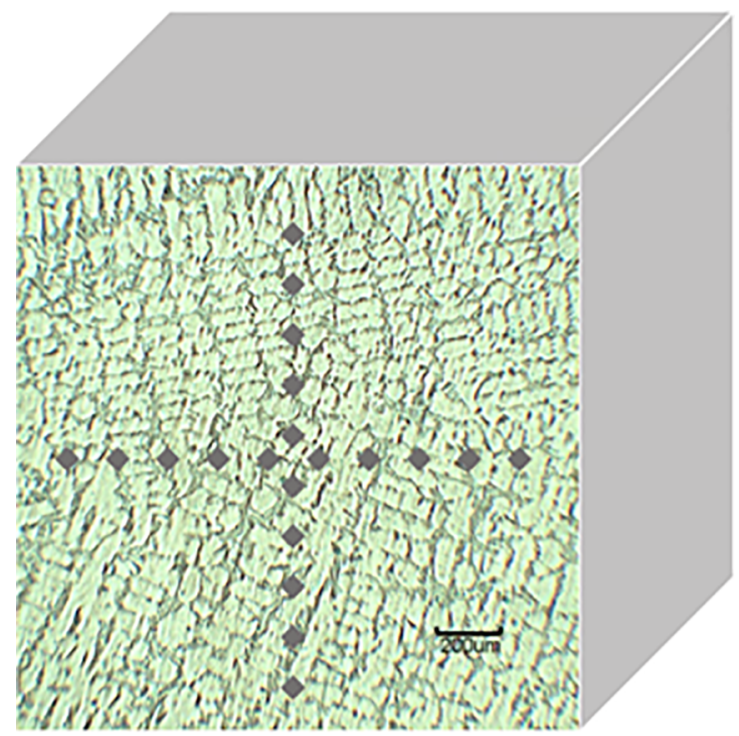

Figure 4. Representative scheme of HV measurements in as-cast and heat-treated samples of the investigated alloy in this work.

\section{Results and Discussion}

Typical microstructures of as-cast and heat-teated samples of the investigated alloy are shown in Figure 5. It is observed that the secondary dendrite arm spacings were sufficiently distinct to make reasonably accurate measurements along the casting length. Figure 6 shows the average (and, minimum and maximum) $\lambda_{2}$ experimental values as a function of distance from the metal-mold interface. It is evidenced $\lambda_{2}$ increase with the distance from the heat-extracting surface. This can be explained by the fact that the use of a watercooled mold imposes higher values of tip growth rates and cooling rates near the casting surface and a decreasing profile along the casting due to the increasing thermal resistance of the solidified shell with distance from the cooled surface. However, the T6-heat treatment applied in the as-cast samples has not affected the secondary dendritic spacing. This can be confirmed by the Figure 6 that a single dendritic growth law has been found for both as-cast and heat-treated samples, give by $\lambda_{2}=6.8(\mathrm{P})^{0.44}$.

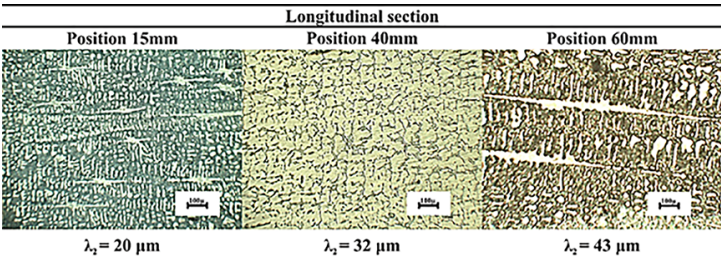

(a)

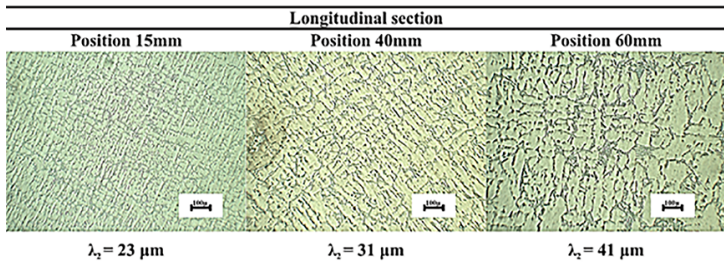

(b)

Figure 5. Revealed micrographs of the investigated alloy, showing the dendritic microstructures of the samples: (a) as-cast and (b) heat-treated

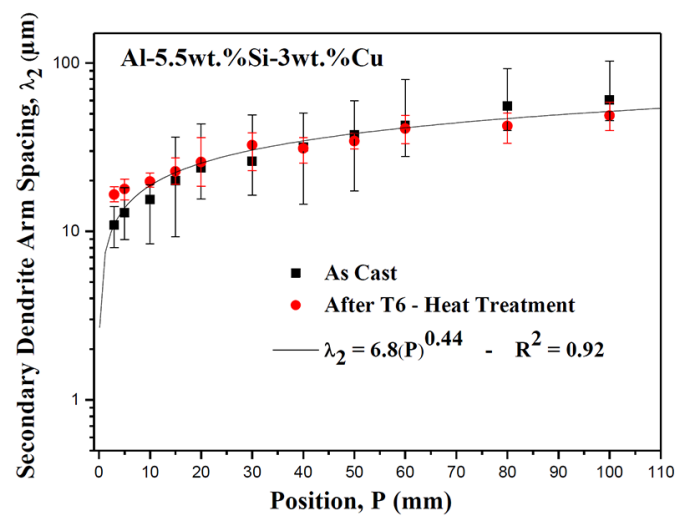

Figure 6. Correlation between the secondary dendrite arm spacing with liquid isotherm position.

In order to analyze the combined effects of the dendritic microstructure and the solution heat treatment on the change of Si morphology, a more detailed analysis of the optical microstructures of two position of each sample (as-cast and heat-treated) has been carried out using an image processing software (Image J) and Figure 7 shows the resulting microstructures. It is observed that the operational parameters (temperature and time) established for the solution treatment applied in this work have been more efficient for refined dendritic structures, i.e., for smaller $\lambda_{2}$ values, since more spheroidized Si particles have been obtained in positions closer to the cooled interface.

The dependence of the microhardness (HV) with the distance (P) from the metal/mold interface can be seen in Figure 8 . It 

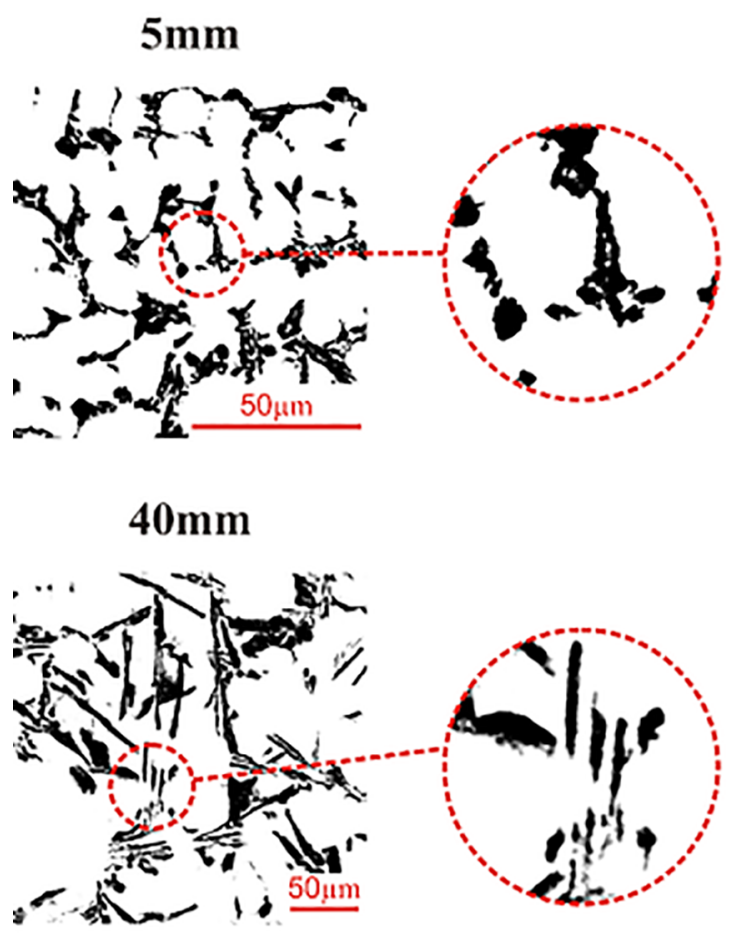

(a)

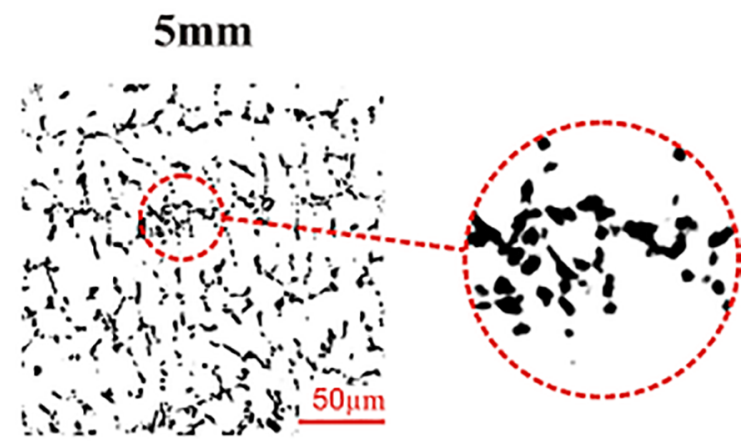

$40 \mathrm{~mm}$

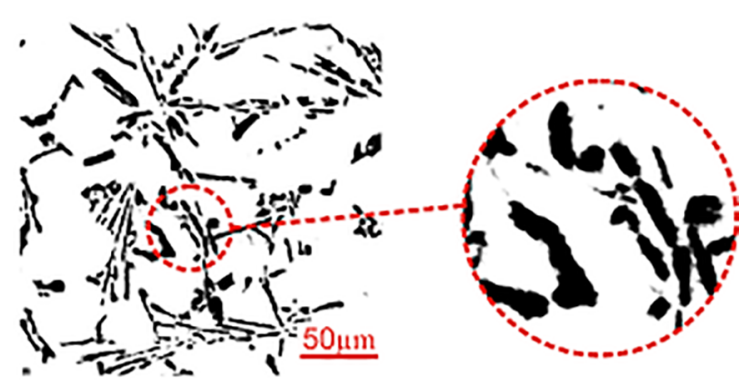

(b)

Figure 7. Typical microstructures of the as-cast and heat-treated samples. Si particle analysis in positions: (a) $5 \mathrm{~mm}$ and (b) $40 \mathrm{~mm}$, in relation to the metal/mold interface, respectively.

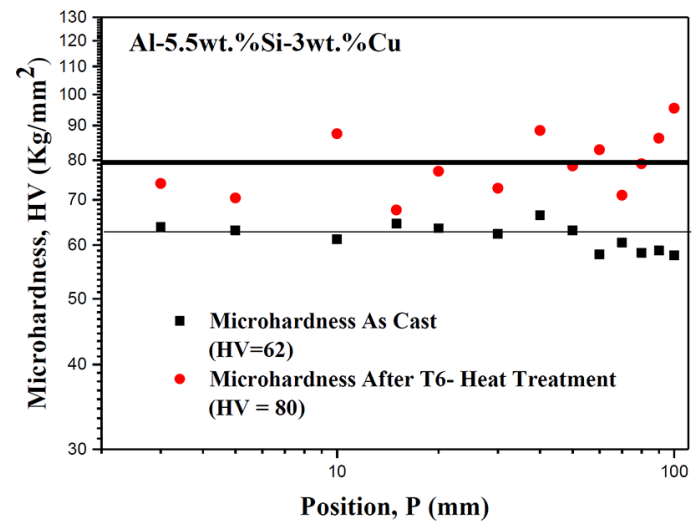

Figure 8. HV dependence as a function of $\lambda_{2}$ for the assumed conditions in this work: Effect of T6-heat treatment on as-cast samples.

can be observed that the HV values remain constant with the position variation, giving average experimental values equal to $62 \mathrm{~kg} / \mathrm{mm}^{2}$ and $80 \mathrm{~kg} / \mathrm{mm}^{2}$ for the investigated samples (as-cast and submitted to the T6 heat treatment, respectively). This also can be seen higher HV values (approximately 36 percent of increase in hardness) for the samples that have been subjected to the T6-heat treatment due to precipitation of the metastable $\mathrm{Al}_{2} \mathrm{Cu}$ phase in the Al-rich matrix during the artificial aging process.

\section{Conclusion}

The following major conclusions can be drawn from the present study:

1. It has been found that the T6-heat treatment has not affected the secondary dendritic spacings of the as-cast samples and that a single experimental power law has been proposed to predict the $\lambda_{2}$ variation with the position from the metal $/ \mathrm{mold}$ interface.

2. Si particles are better spheroidized for more refined dendritic microstructures, i.e., for lower $\lambda_{2}$ values.

3. The values found for HV have shown that the T6heat treatment applied in the horizontally solidified aluminum-based multicomponent 319 alloy in this work has resulted in the increase of its mechanical strength, considering the higher HV values observed in the heat-treated samples. 


\section{Acknowledgments}

The authors acknowledge the financial support provided by IFPA - Federal Institute of Education, Science and Technology of Pará, UFPA - Federal University of Pará, and CNPq - The Brazilian Research Council (grants 472745/2013-1 and 308784/2014-6), FAPESPA - Amazon Foundation of Support to Study and Research (grants ICAAF 064/2016) and CAPES - Coordination of Superior Level Staff Improvement, Brazil.

\section{References}

1. Costa TA, Dias M, Gomes LG, Rocha OL, Garcia A. Effect of solution time in T6 heat treatment on microstructure and hardness of a directionally solidified Al-Si-Cu alloy. Journal of Alloys and Compounds. 2016;683:485-494.

2. Tash M, Samuel FH, Mucciardi F, Doty HW. Effect of metallurgical parameters on the hardness and microstructural characterization of as-cast and heat-treated 356 and 319 aluminum alloys. Materials Science and Engineering: A. 2007;443(1-2):185-201.

3. Sjölander E, Seifeddine S. The heat treatment of Al-Si-Cu-Mg casting alloys. Journal of Materials Processing Technology. 2010;210(10):1249-1259.

4. Bouchard D, Kirkaldy JS. Prediction of dendrite arm spacings in unsteady-and steady-state heat flow of unidirectionally solidified binary alloys. Metallurgical and Materials Transactions $B$. 1997;28(4):651-663.

5. Araújo RLM, Kikuchi RHL, Barros AS, Gomes LG, Moutinho DJC, Gonçalves FA, et al. Influence of upward and horizontal growth direction on microstructure and microhardness of an unsteady-state directionally solidified Al-Cu-Si alloy. Matéria (Rio de Janeiro). 2016;21(1):260-269.

6. Araújo RLM. Parâmetros Térmicos, Espaçamento Dendríticos Primários e Microdureza durante a Solidificação Direcional Horizontal de uma Liga Al-Cu-Si. Belém: Universidade Federal do Pará; 2015.
7. Jerry HS, Djurdjevic MB, Kierkus CA, Northwood DO. Improvement of 319 aluminum alloy casting durability by high temperature solution treatment. Journal of Materials Processing Technology. 2001;109(1-2):174-180.

8. Rocha OFL. Análise Teórico-Experimental da Transição Celular/Dendrítica e da Evolução da Morfologia Dendrítica na Solidificação Unidirecional em Condições de Fluxo de Calor Transitório. [Tese]. Campinas: Universidade Estadual de Campinas; 2003.

9. Çadirli E. Effect of solidification parameters on mechanical properties of directionally solidified Al-Rich Al-Cu alloys. Metals and Materials International. 2013;19(3):411-422.

10. Kaya H, Çadirli E, Böyük U, Marasli N. Variation of microindentation hardness with solidification and microstructure parameters in the Al based alloys. Applied Surface Science. 2008;255(5 Pt 2):3071-3078.

11. Barros AS, Magno IA, Souza FA, Mota CA, Moreira AL, Silva MA, et al. Measurements of microhardness during transient horizontal directional solidification of Al-Rich Al-Cu alloys: Effect of thermal parameters, primary dendrite arm spacing and $\mathrm{Al}_{2} \mathrm{Cu}$ intermetallic phase. Metals and Materials International. 2015;21(3):429-439.

12. Guimarães EC. Influência de Parâmetros Térmicos e espaçamentos Dendriticos Secundários na Microdureza de Ligas Hipoeutéticas Al-Si Direcionalmente Solidificadas sob Condições Transientes. [Dissertação]. Belém: Universidade Federal do Pará; 2014.

13. ASTM International. ASTM E384-99 - Standard Test Method for Microindentation Hardness of Materials. West Conshohocken: ASTM International; 1999.

14. ASTM International. ASTM E-92-82(1997)e3 - Standard Test Methods For Vickers Hardness of Metallic Materials. West Conshohocken: ASTM International; 1997.

15. ASM International. ASM Handbook Volume 2: Properties and Selection: Nonferrous Alloys and Special-Purpose Materials. Materials Park: ASM International; 1990. 